\title{
Symposium
}

\section{Cognition Enhancement Strategies}

\author{
James A. Bibb, ${ }^{1}$ Mark R. Mayford, ${ }^{2}$ Joe Z. Tsien, ${ }^{3}$ and Cristina M. Alberini ${ }^{4}$ \\ ${ }^{1}$ Department of Psychiatry, University of Texas Southwestern Medical Center, Dallas, Texas 75390, ${ }^{2}$ Department of Cell Biology, The Scripps Research \\ Institute, La Jolla, California 92037, ${ }^{3}$ Brain and Behavior Discovery Institute, School of Medicine, Medical College of Georgia, Augusta, Georgia 30912, \\ and ${ }^{4}$ Department of Neuroscience, Mount Sinai School of Medicine, New York, New York 10029
}

Many mental disorders and neurodegenerative and neurodevelopmental diseases involve cognitive deficits. Remarkable advances and new technologies are providing a clearer picture of the molecular basis of cognition. In conjunction with an SFN2010 symposium, we provided here a brief overview of the molecular mechanisms of cognition, with emphasis on the development of treatments for cognitive disorders. Activity-dependent changes in gene expression and protein synthesis integrate with synapse selection to form memory circuits. A neuronal activity-dependent molecular tagging system that uses the gene expression program to record memory circuit formation represents one new tool to study cognition. Regulation of protein translation, protein degradation, cytoskeletal dynamics, extracellular matrix interactions, second messenger signaling, and neurotransmitter receptor trafficking and function are all components of synaptic remodeling essential for cognition. Selective targeting of specific effectors in these processes, such as NMDA receptors, may serve as an effective strategy to treat cognitive deficits.

Deficits in intellectual function are comorbid with many mental illnesses and neurological disorders. Mental retardation, autism, attention deficit disorder, schizophrenia, and depression all have cognitive components, as do Alzheimer's, Parkinson's, Huntington's, and other neurodegenerative diseases. Furthermore, cognitive decline and memory impairment accompanies age-related changes in the brain and can indicate the onset of dementia (Bishop et al., 2010). Cognitive enhancement is viewed as a strategy to treat these diseases or to slow the effects of aging on brain function.

Cognitive enhancement by pharmacological agents is not a new practice. Self-administered psychostimulants such as caffeine and nicotine can improve cognitive performance. Methylphenidate and other medications have proven effective in treating attention disorders. However, not all learning and memory problems may be addressed by stimulants. More effective and precise therapeutic strategies are needed. There are a myriad of possible causes for cognitive disorders. The list of genetic mutations associated with cognitive impairment grows rapidly, and the more controversial genetic basis of cognitive ability has found purchase (Deary et al., 2010). Regardless of the many causes, an efficient strategy to treat the different forms of cognitive deficiency would be to target overarching mechanisms that have clear positive effects on cognitive function (Lee and Silva, 2009).

Received Aug. 23, 2010; revised Sept. 3, 2010; accepted Sept. 7, 2010.

This work was supported by National Institutes of Health grants to J.A.B. (MH79710, MH083711-01, and DA016672), M.R.M. (MH078833, MH057368, and DA0283000), J.Z.T. (MH060236, AG024022, AG034663, and AG025918) and C.M.A. (MH065635 and MH074736). Support was provided from USAMRA00002 and Georgia Research Alliance to J.Z.T. This work was also supported by National Alliance for Research on Schizophrenia and Depression, the Hirschl Foundation, and Philoctetes Foundation awards to C.M.A. We thank Florian Plattner for helpful suggestions and discussions during the preparation of this manuscript.

Correspondence should be addressed to James A. Bibb, Department of Psychiatry, University of Texas Southwestern Medical Center, 5323 Harry Hines Boulevard, NC5.410, Dallas, TX75390-9070. E-mail: james.bibb@utsouthwestern.edu. DOI:10.1523/JNEUROSCI.4419-10.2010

Copyright $\odot 2010$ the authors $\quad 0270-6474 / 10 / 3014987-06 \$ 15.00 / 0$
Therefore, it may prove useful to consider the interrelated processes and factors that contribute to cognition (Fig. 1)

\section{Genes}

As with most noninfectious diseases, understanding of the etiology of cognitive deficits may begin with genes. Clearly, genetic make-up influences cognitive ability, but a number of interrelated factors, including environment and psychological state, affect comprehension and the ability to commit experiences to memory. In addition, the overall state of health or physiological conditions can affect the processes that mediate learning. Hormones in the brain and periphery affect learning, and the endocrine, neuroendocrine, and humoral systems "talk" to the brain. Stress contributes to numerous mental disorders and impairs cognition. Exercise may promote cognition (Lautenschlager et al., 2008) and both stress and exercise may affect the resiliency of the nervous system by affecting neuronal replacement via neurogenesis (van Praag, 2008).

\section{Epigenetics}

Beyond genes and external factors outside the inherent processes of the brain, what are the key aspects to consider when contemplating cognitive enhancement strategies? Over one hundred years of study have contributed to a refined and rapidly growing understanding of the neurobiological basis of learning and memory. Cognition may be viewed as the product of several interrelated general processes that feed both forward and backward onto downstream and upstream effectors, respectively (Fig. 1). An individual's genetic compliment is subserved by a mitotically heritable level of global gene expression known as epigenetics (Delcuve et al., 2009). Key mediators of epigenetic control include DNA methylation and histone posttranslational modifications. Epigenetics has emerged as an important aspect of learning and mental illnesses (Nestler, 2009). Prenatal and postnatal neurodevelopment relies on epigenetics to establish the neuronal 
architecture and synaptic matrix, and to initiate the selective pruning and strengthening of synapses that underlie learning. Lost memories may be reaccessed by increasing gene expression by targeting histone acetylation (Guan et al., 2009). HDAC inhibitors are viewed as promising treatments for cognitive deficits (Kilgore et al., 2010), although more specific mechanistic aspects of epigenetic regulation are needed.

\section{Gene expression and signaling}

Epigenetic programming is subserved by the overall process of gene expression. Synaptic stimulation triggers signaling cascades that feed back to RNA polymerase activity and its ability to increase or decrease the generation of mRNA transcripts of specific genes. Thus, in response to experience-induced activation of neural circuitry, profiles of gene expression are altered. Cognition involves synaptic activitydependent initiation of transcription of immediate early genes (IEGs) that direct de novo protein synthesis that is essential for long-term memory formation. Transcription factors are key to this aspect of cognition (Alberini, 2009). The cAMP response element binding protein (CREB) is the prototypical example of these regulatory transcription factors. CREB is activated when synaptic activity induces its phosphorylation at Ser 133 by protein kinases such as cAMP-activated PKA or $\mathrm{Ca}^{2+}$-actviated members of the CaM kinase family. CREB then regulates the rate by which target genes are transcribed. Among these target genes, there are other transcription factors such as CCAAT enhancer binding proteins (C/EBPs) that amplify the gene cascade. Phosphorylation of Ser133 promotes the binding of CREB to a CREBbinding protein, allowing CREB to interact with the RNA polymerase II complex to initiate, or not initiate, gene transcription. Phospho-CREB serves as one well recognized marker of neuronal gene cascade activation. AP1 is another transcriptional factor composed of proteins belonging to the c-Fos, c-Jun, ATF, and JDP families that regulate gene expression. AP1-like factors respond to a variety of stimuli and neuronal signaling pathways that invoke MAP kinase cascades. Hormones, growth factors, cytokines, and stress regulate $\mathrm{CREB}, \mathrm{C} / \mathrm{EBP}$, and $\mathrm{AP} 1$ activities, providing an example of how external factors affect cognitive mechanisms. $\mathrm{NF} \kappa \mathrm{B}$ is another transcriptional factor activated in response to neuronal activity that affects the expression of synaptic proteins such as CaMKII (Alberini, 2009).

As prototypical mechanisms, these pathways provide insight into this targetable aspect of cognition. However, the number of genes containing these sequences may be in the thousands. Furthermore, CREB activation has been reported for many forms of physiological and environmental stimuli and many pathways feed into its activation or inactivation. Thus, it will be important to delineate presently unknown transcriptional regulation pathways to better understand which mechanisms present the most drugable targets for therapeutic development.

Once activity-dependent gene expression has been initiated, a plethora of IEG and target gene transcripts are generated and translated to proteins. The de novo synthesized proteins encoded by IEGs frequently have short half-lives and mediate synaptic remodeling by controlling a variety of processes. Some factors feed back to mediate further gene expression. An example is $\mathrm{Zif}$
268 (or early growth response protein 1), which marks neuronal activation and contributes to learning and plasticity. The invocation of transient Zif 268 expression in response to synaptic activity is dependent upon activation of the NMDA class of excitatory ionotropic glutamate receptors (see below). Activity-regulated cytoskeleton-associated protein (ARC) represents another important IEG that appears to play a number of roles in synaptic remodeling and is required for memory consolidation (Miyashita et al., 2008). Other IEGs and target genes affect structural components of synapses and cytoskeletal dynamics, protein trafficking, protein degradation, protein phosphorylation/dephosphorylation, and mRNA stability. The list of important IEGs continues to grow. One previously uncharacterized regulated transcript that appears to mediate cognition and shows promise as a target for memory enhancement is insulin-like growth factor II (C. Alberini et al., manuscript in preparation).

\section{The neuronal structural network}

Gene expression contributes to, and is regulated by, the process of synaptic remodeling. Strong synaptic activity invokes molecular and structural changes in synapses so that they are strengthened or weakened. In response to experience, synaptic activity and consequent remodeling results in the formation of neural circuits that encode representations of the experience. A prerequisite to memory formation is the development of the structural matrix composed of neurons and their synapses. The synaptic connections forming this network must be responsive to activity-dependent changes. Perturbations in the formation of the synaptic network during development, injury of neurons possessing synaptic arbors, dysregulation of synaptic plasticity, or the inability to maintain the network structure across lifespan may underlie human neurological and neuropsychiatric disorders.

One current area of inquiry pertains to the fact that during learning only a tiny fraction of the neurons in the brain are used for any particular memory trace or neural representation (Reijmers and Mayford, 2009). As information about the gene cascade underlying memory has emerged, it has provided tools with which to develop new technology to study and identify the mechanisms linking gene expression to synaptic remodeling. As one approach to the molecular study of those specific neurons, elements of the tet gene regulation system have been combined with promoters that are activated by high-level neural activity such as that of the IEG $c$ Fos to generate mouse models in which a 
genetic tag can be introduced into neurons that are active at a given point in time (Reijmers et al., 2007). The tag may be maintained for a prolonged period, creating a precise record of the neural activity pattern during a specific experience. Combined with behavioral paradigms of learning, this approach has demonstrated that the same neurons activated during learning are reactivated when an animal recalls an adverse experience (Reijmers et al., 2007). Furthermore, these neurons are no longer activated following a form of cognition known as memory extinction, consistent with the idea that extinction modifies a component of the original memory trace. In other studies using neuronal activitydependent activation of immediate early genes to understand how synapses become tagged with learning, the cFos transgenic approach was used to express glutamate receptors in activated neuronal ensembles. The newly synthesized receptors were specifically targeted to a subset of synapses, demonstrating one mechanism of nucleus-to-synapse communication (Matsuo et al., 2008). The results suggest that, similar to what had been seen in synaptic plasticity paradigms (Frey and Morris, 1997), behavioral learning produced a molecular tag at certain synapses that allowed them to capture the newly synthesized receptors arriving from the soma hours after the learning event. Thus, the synapses that are altered in strength to produce a short-term memory must be primed, or tagged, to receive new receptors, allowing for the maintenance of the memory.

\section{Synaptic remodeling}

Synaptic plasticity and remodeling collectively represents another prominent component of cognition. Reorganization within the presynaptic and postsynaptic compartments, and the extracellular milieu that surrounds the synapse, occurs in response to activity. Experience-dependent activity may induce a metaplastic state through which activated synapses must pass if they are to strengthen and form circuits (Abraham, 2008; Lee et al., 2010). This selective transition of specific synapses involves activity-dependent changes that are facilitated by, or dependent on, changes in gene expression and protein translation during the consolidation process. An important phase in the transition from naive to strong synapse is thought to involve activity-dependent increases in synaptic efficiency. This is called long-term potentiation (LTP), with the reverse process termed long-term depression. The induction of these changes in synaptic efficiency may represent a state of metaplasticity during which synaptic remodeling continues over time and memory is consolidated (Abraham and Bear, 1996). Synaptic remodeling involves a number of processes that may be considered as potential targets for cognitive therapies. These processes are highly regulated by signal transduction mechanisms and protein phosphorylation/dephosphorylation. The coordination of these complex processes is key to learning and memory.

\section{Protein translation}

Protein synthesis is required for synaptic plasticity and memory (Cajigas et al., 2010). Nuclear transcripts are transported to distal synapses via dendritic-targeting elements in neuronal mRNA. In response to synaptic activity, protein translation is induced and the protein translation profile of a synapse that is being remodeled serves as a synaptic memory consolidation snapshot. Inhibitors of protein synthesis attenuate cognition. As more is learned of the mechanisms controlling synaptic protein translation and mRNA translocation, new targets for cognitive enhancement strategies may be found. Toward this goal, a transgenic technology has been developed, called BacTRAP, which allows isolation of the complete suite of translated cell-type-specific mRNAs (Doyle et al., 2008; Heiman et al., 2008; Dougherty et al., 2010). This system uses bacterial artificial chromosomes to drive expression of ribosomal proteins fused to GFP tags that are then affinity purified with their associated mRNA transcripts. It will be interesting to use this technology to define the profile of activated synapses, and to compare this profile between normal mice and those modeling cognitive disorders such as autism (Silverman et al., 2010).

\section{Protein degradation}

Synaptic remodeling involves changes in the synaptic proteome. In addition to protein synthesis, selective protein degradation is an important aspect of cognition. The ubiquitin proteosome system localizes to synapses (Bingol et al., 2010) and its activation during synaptic activity is essential to plasticity and learning (Cajigas et al., 2010). NMDA receptor activation mediates redistribution of proteasome subunits. In addition to proteasomes, $\mathrm{Ca}^{2+}$-activated protein phosphatases such as calpain appear to be inherently involved in synaptic remodeling. Calpain cleaves the NR2B subunit of NMDA receptors (Guttmann et al., 2002), NF $\kappa \mathrm{B}$ (Schölzke et al., 2003), p35 (the activating cofactor of Cdk5), striatal-enriched protein tyrosine phosphatase (STEP) (Xu et al., 2009), and the actin-regulating protein, spectrin (Lynch et al., 2007), as well as an array of post and presynaptic proteins (Liu et al., 2006).

\section{Cytoskeletal dynamics}

The actin cytoskeleton underlies synaptic structure and actin polymerization/depolymerization dynamics are an inherent aspect of synaptic remodeling. Small GTPase family members (RhoA, Rac1, and Cdc42) regulate downstream effectors, including p21activated kinases PAK1 and PAK3, that then alter actin structure through the LIM kinase-cofilin pathway (Scott and Olson, 2007). Cofilin destabilizes actin when phosphorylated by LIM kinase. In regulating actin dynamics, cofilin interacts with the ARP $2 / 3$ complex. WAVE1, a member of the Wiskott-Aldrich syndrome protein family, also regulates actin dynamics and is the effector of synaptic signaling kinases, including PKA and Cdk5 (Ceglia et al., 2010). Spectrin is a cytoskeletal protein that lines the intracellular side of the plasma membrane, forming a scaffold and playing an important role in maintenance of plasma membrane integrity and cytoskeletal structure (Huh et al., 2001). Its activitydependent cleavage by calpain may also contribute to synaptic remodeling. Dysregulation of the actin cytoskeleton is associated with mental retardation and cognitive deficits. Because of its many roles in synaptic function and remodeling, actin dynamics regulation is an attractive target for memory enhancement strategies.

\section{Extracellular matrix}

The transmembrane proteins of neurons and their synapses, like all cells in tissue, undergo posttranslational and translocationcoordinated modifications, such as glycosylation and interaction with the extracellular matrix. The morphogenic processes by which synapses remodel and change physical shape likely includes regulation of extracellular matrix interactions. For example, integrins are transmembrane cell adhesion receptors that mediate cell-matrix and cell-cell interactions, and link the external environment of the cell to its internal cytoarchitectural components. The cytoplasmic domains of these proteins, which have been suggested to regulate synaptic stability, interact with many signaling molecules to transduce information bidirectionally across the plasma membrane. Integrins can regulate ion channel 
activity through signaling pathways that often include tyrosine phosphorylation cascade. Furthermore, integrins cross talk with ionotropic glutamate receptors (Morini and Becchetti, 2010). Accumulating evidence implicates integrin function in synaptic and behavioral plasticity. Mice with reduced expression of the $\alpha 3-, 5-$, and 8-integrin subunits are defective in hippocampusdependent spatial memory (Chan and Davis, 2008), and $\alpha 8$ integrins are required for hippocampal long-term potentiation (Chan et al., 2010). Integrins may also affect synaptic activity through regulation of voltage-gated $\mathrm{Ca}^{2+}$ channels (Gui et al., 2006). Other posttranslational modifications of transmembrane proteins affect their interactions with the perineuronal net of extracellular matrix molecules and may also serve as a point to enhance cognition. For example, enzymatic removal of hyaluronic acid modulates short-term plasticity and facilitates induction of LTP by increasing the activity of L-type voltage-dependent $\mathrm{Ca}^{2+}$ channels (Kochlamazashvili et al., 2010). In contrast, removal of chondroitin sulfate reduces LTP at hippocampal excitatory synapses (Bukalo et al., 2001).

\section{Second messenger signaling}

It is likely that most, if not all, synapses are capable of activitydependent remodeling. Excitatory neurotransmission may be balanced with inhibitory activity, and ionotropic receptormediated activity is clearly regulated by metabotropic and G-protein coupled signaling. The presynaptic and postsynaptic compartment must integrate the activity of numerous second messengers such as $\mathrm{Ca}^{2+}$, cyclic nucleotides, lipid metabolites, and phosphoinositides, all of which trigger signaling cascades involving protein phosphorylation/dephosphorylation, protein/ protein interactions, and protein synthesis/degradation. Intracellular signal transduction mediators represent important targets for cognition enhancement. For example, inhibition of the phosphodiesterase 4 family of enzymes that degrade cAMP by rolipram enhances synaptic plasticity, improves cognition, and has antidepressant effects in humans (O'Donnell and Zhang, 2004; Kleppisch, 2009). However, rolipram's negative side effects of nausea and emesis conspire against its effective deployment in the clinic and demonstrate the need for more selective targeting strategies (Houslay et al., 2005).

\section{Receptor trafficking and modulation}

Excitatory neurotransmitter receptors represent the front line in the molecular mechanisms of cognition. Ionotropic glutamate receptors, for example, consist of two main types, AMPA and NMDA receptors. AMPA receptors conduct the fast excitatory currents that trigger the formation of action potentials in response to glutamate binding (Malinow and Malenka, 2002). They are heterotetrameric complexes comprised of at least two of four subunits, GluR1-4. Each subunit confers specific properties on their function in glutamate-gated cation conductance. For example, GluR2-containing receptors do not conduct $\mathrm{Ca}^{2+}$. Each subunit is regulated through phosphorylation/dephosphorylation, interacts with scaffolding partners and components of the postsynaptic density, and is rapidly transported in and out of the synapses to strengthen or weaken their action during plasticity and learning (Choquet, 2010). Substantial evidence points to these mechanisms being disrupted in cognitive disorders (Keifer and Zheng, 2010). A number of AMPA receptor agonists have shown promise for cognitive enhancement therapy. For example, a class of positive allosteric modulators of AMPA receptors, called Ampakines, improves plasticity and cognition in animals and humans (Lynch, 2002).
NMDA receptors represent another important class of ionotropic glutamate receptors that are essential for cognition and synaptic plasticity. Like AMPA receptors, they are heteromeric and are composed of NR1, NR2, and NR3 subunits. However, unlike AMPA receptors, their activity is not solely dependent upon glutamate binding. In addition, the receptors must also complex with glycine via an obligatory NR1 subunit and are only active during membrane depolarization, when a voltage-dependent block by $\mathrm{Mg}^{2+}$ is relieved (Cull-Candy and Leszkiewicz, 2004). Thus, NMDA receptors function as detectors of coincident presynaptic and postsynaptic activity and are highly permeable to $\mathrm{Ca}^{2+}$, which invokes downstream signaling cascades.

The kinetic characteristics of specific NR2 subunits may also distinguish their contributions to plasticity. For example, dimeric NMDA receptors (NMDARs) containing NR2A subunits are characterized by high open channel probabilities and rapid inactivation. In contrast, NR2B-containing receptors have a lower open probability but slower inactivation kinetics (Cull-Candy and Leszkiewicz, 2004). Membrane protein trafficking is also important in regulating NMDAR constituency (Lau and Zukin, 2007). Functional NMDAR assembly occurs in the endoplasmic reticulum. Targeting of receptors to the synapse is mediated by interactions between the cytoplasmic tail of NR2 receptors and other proteins such as membrane-associated guanylate kinases, including PSD-95, PSD-93, and SAP102 (Sheng and Sala, 2001). Interactions with endocytic machinery also facilitate internalization (Wenthold et al., 2003). A number of phosphorylation sites have been suggested to affect the function or trafficking of NMDAR subunits. (Leonard et al., 1999; Chung et al., 2004).

The distinct properties conferred on NMDA receptor subunits point to the dynamic regulation of their constituency as a component of cognition. For example, NR2A subunits may be responsible for plasticity during high-frequency stimulation events, whereas NR2B subunits may be used during lower frequency stimulation. Furthermore, neurotransmission through NR2B-containing NMDARs induces the upregulation of NR2A subunits, indicating that there may be activity-dependent subunitspecific insertion of NMDA receptors (Bellone and Nicoll, 2007). It's possible that NR2B-containing receptors are present at immature or more plastic synapses and activity through these synapses recruits NR2A-containing subunits to maintain potentiation and allow higher frequency stimulation. Indeed, NMDARs are typically NR1/ NR2B heteromers early in development, but the subunit composition is developmentally regulated with NR2A expression increasing over time (Monyer et al., 1994; Sans et al., 2000; Tang et al., 2010).

A large body of work indicates NMDA receptors are crucial to cognition. For example, mice that overexpress NR2B show increased cognition and enhanced plasticity (Tang et al., 1999; Cao et al., 2007), and the induction of LTP in the hippocampus of awake, freely moving rats increases NR2B levels (Williams et al., 1998). NR2B receptors are also degraded by calpain in an activitydependent manner, and this appears to involve structural interactions with Cdk5 (Hawasli and Bibb, 2007). Conditional knock-out of Cdk5 in mice increased NR2B levels and resulted in enhanced plasticity and cognition (Hawasli et al., 2007). NMDA receptor agonists show promise for cognitive enhancement therapy. For example, the partial NMDA receptor agonist, D-cycloserine, has cognition-enhancing properties for models of Parkinson's disease in primates (Schneider et al., 2000) and may be considered for treatment of schizophrenia (Tamminga, 2006). Interestingly, an NMDA receptor antagonist, memantine, has also shown some efficacy in slowing the course of some Alzheimer's dis- 
ease symptoms, possibly via anti-excitotoxic actions (Mount and Downton, 2006).

In summary, our understanding of the processes that contribute to neurotransmission has grown immensely. A complex picture is beginning to come into focus. As we learn of the many processes involved, including the examples highlighted here, it is becoming clear that dysregulation of these processes underlies cognitive disorders. Consequently, it is now possible to develop more sophisticated strategies to treat cognitive disorders.

\section{References}

Abraham WC (2008) Metaplasticity: tuning synapses and networks for plasticity. Nat Rev Neurosci 9:387.

Abraham WC, Bear MF (1996) Metaplasticity: the plasticity of synaptic plasticity. Trends Neurosci 19:126-130.

Alberini CM (2009) Transcription factors in long-term memory and synaptic plasticity. Physiol Rev 89:121-145.

Bellone C, Nicoll RA (2007) Rapid bidirectional switching of synaptic NMDA receptors. Neuron 55:779-785.

Bingol B, Wang CF, Arnott D, Cheng D, Peng J, Sheng M (2010) Autophosphorylated CaMKIIalpha acts as a scaffold to recruit proteasomes to dendritic spines. Cell 140:567-578.

Bishop NA, Lu T, Yankner BA (2010) Neural mechanisms of ageing and cognitive decline. Nature 464:529-535.

Bukalo O, Schachner M, Dityatev A (2001) Modification of extracellular matrix by enzymatic removal of chondroitin sulfate and by lack of tenascin- $\mathrm{R}$ differentially affects several forms of synaptic plasticity in the hippocampus. Neuroscience 104:359-369.

Cajigas IJ, Will T, Schuman EM (2010) Protein homeostasis and synaptic plasticity. EMBO J 29:2746-2752.

Cao X, Cui Z, Feng R, Tang YP, Qin Z, Mei B, Tsien JZ (2007) Maintenance of superior learning and memory function in NR2B transgenic mice during ageing. Eur J Neurosci 25:1815-1822.

Ceglia I, Kim Y, Nairn AC, Greengard P (2010) Signaling pathways controlling the phosphorylation state of WAVE1, a regulator of actin polymerization. J Neurochem 114:182-190.

Chan CS, Davis RL (2008) Integrins and cadherins: extracellular matrix in memory formation. In: Learning and memory: a comprehensive reference (Byrne JH, ed), pp 721-740. Burlington, MA: Elsevier.

Chan CS, Chen H, Bradley A, Dragatsis I, Rosenmund C, Davis RL (2010) Alpha8-integrins are required for hippocampal long-term potentiation but not for hippocampal-dependent learning. Genes Brain Behav 9:402-410.

Choquet D (2010) Fast AMPAR trafficking for a high-frequency synaptic transmission. Eur J Neurosci 32:250-260.

Chung HJ, Huang YH, Lau LF, Huganir RL (2004) Regulation of the NMDA receptor complex and trafficking by activity-dependent phosphorylation of the NR2B subunit PDZ ligand. J Neurosci 24:10248-10259.

Cull-Candy SG, Leszkiewicz DN (2004) Role of distinct NMDA receptor subtypes at central synapses. Sci STKE 2004:re16.

Deary IJ, Penke L, Johnson W (2010) The neuroscience of human intelligence differences. Nat Rev Neurosci 11:201-211.

Delcuve GP, Rastegar M, Davie JR (2009) Epigenetic control. J Cell Physiol 219:243-250.

Dougherty JD, Schmidt EF, Nakajima M, Heintz N (2010) Analytical approaches to RNA profiling data for the identification of genes enriched in specific cells. Nucleic Acids Res 38:4218-4230.

Doyle JP, Dougherty JD, Heiman M, Schmidt EF, Stevens TR, Ma G, Bupp S, Shrestha P, Shah RD, Doughty ML, Gong S, Greengard P, Heintz N (2008) Application of a translational profiling approach for the comparative analysis of CNS cell types. Cell 135:749-762.

Frey U, Morris RG (1997) Synaptic tagging and long-term potentiation. Nature 385:533-536.

Guan JS, Haggarty SJ, Giacometti E, Dannenberg JH, Joseph N, Gao J, Nieland TJ, Zhou Y, Wang X, Mazitschek R, Bradner JE, DePinho RA, Jaenisch R, Tsai LH (2009) HDAC2 negatively regulates memory formation and synaptic plasticity. Nature 459:55-60.

Gui P, Wu X, Ling S, Stotz SC, Winkfein RJ, Wilson E, Davis GE, Braun AP, Zamponi GW, Davis MJ (2006) Integrin receptor activation triggers converging regulation of Cav1.2 calcium channels by c-Src and protein kinase A pathways. J Biol Chem 281:14015-14025.
Guttmann RP, Sokol S, Baker DL, Simpkins KL, Dong Y, Lynch DR (2002) Proteolysis of the $N$-methyl-D-aspartate receptor by calpain in situ. J Pharmacol Exp Ther 302:1023-1030.

Hawasli AH, Bibb JA (2007) Alternative roles for Cdk5 in learning and synaptic plasticity. Biotechnol J 2:941-948.

Hawasli AH, Benavides DR, Nguyen C, Kansy JW, Hayashi K, Chambon P, Greengard P, Powell CM, Cooper DC, Bibb JA (2007) Cyclindependent kinase 5 governs learning and synaptic plasticity via control of NMDAR degradation. Nat Neurosci 10:880-886.

Heiman M, Schaefer A, Gong S, Peterson JD, Day M, Ramsey KE, SuárezFariñas M, Schwarz C, Stephan DA, Surmeier DJ, Greengard P, Heintz N (2008) A translational profiling approach for the molecular characterization of CNS cell types. Cell 135:738-748.

Houslay MD, Schafer P, Zhang KY (2005) Keynote review: phosphodiesterase-4 as a therapeutic target. Drug Discov Today 10:1503-1519.

Huh GY, Glantz SB, Je S, Morrow JS, Kim JH (2001) Calpain proteolysis of alphaII-spectrin in the normal adult human brain. Neurosci Lett 316:41-44.

Keifer J, Zheng Z (2010) AMPA receptor trafficking and learning. Eur J Neurosci 32:269-277.

Kilgore M, Miller CA, Fass DM, Hennig KM, Haggarty SJ, Sweatt JD, Rumbaugh G (2010) Inhibitors of class 1 histone deacetylases reverse contextual memory deficits in a mouse model of Alzheimer's disease. Neuropsychopharmacology 35:870-880.

Kleppisch T (2009) Phosphodiesterases in the central nervous system. Handb Exp Pharmacol 191:71-92.

Kochlamazashvili G, Henneberger C, Bukalo O, Dvoretskova E, Senkov O, Lievens PM, Westenbroek R, Engel AK, Catterall WA, Rusakov DA, Schachner M, Dityatev A (2010) The extracellular matrix molecule hyaluronic acid regulates hippocampal synaptic plasticity by modulating postsynaptic L-type $\mathrm{Ca}(2+)$ channels. Neuron 67:116-128.

Lau CG, Zukin RS (2007) NMDA receptor trafficking in synaptic plasticity and neuropsychiatric disorders. Nat Rev Neurosci 8:413-426.

Lautenschlager NT, Cox KL, Flicker L, Foster JK, van Bockxmeer FM, Xiao J, Greenop KR, Almeida OP (2008) Effect of physical activity on cognitive function in older adults at risk for Alzheimer disease: a randomized trial. JAMA 300:1027-1037.

Lee MC, Yasuda R, Ehlers MD (2010) Metaplasticity at single glutamatergic synapses. Neuron 66:859-870.

Lee YS, Silva AJ (2009) The molecular and cellular biology of enhanced cognition. Nat Rev Neurosci 10:126-140.

Leonard AS, Lim IA, Hemsworth DE, Horne MC, Hell JW (1999) Calcium/ calmodulin-dependent protein kinase II is associated with the $\mathrm{N}$-methylD-aspartate receptor. Proc Natl Acad Sci U S A 96:3239-3244.

Liu MC, Akle V, Zheng W, Dave JR, Tortella FC, Hayes RL, Wang KK (2006) Comparing calpain- and caspase-3-mediated degradation patterns in traumatic brain injury by differential proteome analysis. Biochem J 394:715-725.

Lynch G (2002) Memory enhancement: the search for mechanism based drugs. Nat Neurosci 5:1035-1038.

Lynch G, Rex CS, Gall CM (2007) LTP consolidation: substrates, explanatory power, and functional significance. Neuropharmacology 52:12-23.

Malinow R, Malenka RC (2002) AMPA receptor trafficking and synaptic plasticity. Annu Rev Neurosci 25:103-126.

Matsuo N, Reijmers L, Mayford M (2008) Spine-type-specific recruitment of newly synthesized AMPA receptors with learning. Science 319:1104-1107.

Miyashita T, Kubik S, Lewandowski G, Guzowski JF (2008) Networks of neurons, networks of genes: an integrated view of memory consolidation. Neurobiol Learn Mem 89:269-284.

Monyer H, Burnashev N, Laurie DJ, Sakmann B, Seeburg PH (1994) Developmental and regional expression in the rat brain and functional properties of four NMDA receptors. Neuron 12:529-540.

Morini R, Becchetti A (2010) Integrin receptors and ligand-gated channels. Adv Exp Med Biol 674:95-105.

Mount C, Downton C (2006) Alzheimer disease: progress or profit? Nat Med 12:780-784.

Nestler EJ (2009) Epigenetic mechanisms in psychiatry. Biol Psychiatry 65:189-190.

O’Donnell JM, Zhang HT (2004) Antidepressant effects of inhibitors of cAMP phosphodiesterase (PDE4). Trends Pharmacol Sci 25:158-163.

Reijmers L, Mayford M (2009) Genetic control of active neural circuits. Front Mol Neurosci 2:27. 
Reijmers LG, Perkins BL, Matsuo N, Mayford M (2007) Localization of a stable neural correlate of associative memory. Science 317:1230-1233.

Sans N, Petralia RS, Wang YX, Blahos J 2nd, Hell JW, Wenthold RJ (2000) A developmental change in NMDA receptor-associated proteins at hippocampal synapses. J Neurosci 20:1260-1271.

Schneider JS, Tinker JP, Van Velson M, Giardiniere M (2000) Effects of the partial glycine agonist D-cycloserine on cognitive functioning in chronic low dose MPTP-treated monkeys. Brain Res 860:190-194.

Schölzke MN, Potrovita I, Subramaniam S, Prinz S, Schwaninger M (2003) Glutamate activates NF-kappaB through calpain in neurons. Eur J Neurosci 18:3305-3310.

Scott RW, Olson MF (2007) LIM kinases: function, regulation and association with human disease. J Mol Med 85:555-568.

Sheng M, Sala C (2001) PDZ domains and the organization of supramolecular complexes. Annu Rev Neurosci 24:1-29.

Silverman JL, Yang M, Lord C, Crawley JN (2010) Behavioural phenotyping assays for mouse models of autism. Nat Rev Neurosci 11:490-502.

Tamminga CA (2006) The neurobiology of cognition in schizophrenia. J Clin Psychiatry 67:e11.

Tang TT, Badger JD 2nd, Roche PA, Roche KW (2010) Novel approach to probe subunit-specific contributions to $N$-methyl-D-aspartate (NMDA) receptor trafficking reveals a dominant role for NR2B in receptor recycling. J Biol Chem 285:20975-20981.

Tang YP, Shimizu E, Dube GR, Rampon C, Kerchner GA, Zhuo M, Liu G, Tsien JZ (1999) Genetic enhancement of learning and memory in mice. Nature 401:63-69.

van Praag H (2008) Neurogenesis and exercise: past and future directions. Neuromolecular Med 10:128-140.

Wenthold RJ, Prybylowski K, Standley S, Sans N, Petralia RS (2003) Trafficking of NMDA receptors. Annu Rev Pharmacol Toxicol 43:335-358.

Williams JM, Mason-Parker SE, Abraham WC, Tate WP (1998) Biphasic changes in the levels of $N$-methyl-D-aspartate receptor-2 subunits correlate with the induction and persistence of long-term potentiation. Brain Res Mol Brain Res 60:21-27.

Xu J, Kurup P, Zhang Y, Goebel-Goody SM, Wu PH, Hawasli AH, Baum ML, Bibb JA, Lombroso PJ (2009) Extrasynaptic NMDA receptors couple preferentially to excitotoxicity via calpain-mediated cleavage of STEP. J Neurosci 29:9330-9343. 